\title{
SC|AZ
}

\section{O trabalho de pesquisadoras durante a Pandemia da COVID-19: Relatos e Reflexões de Práticas Possíveis}

\author{
Camila Silva Marques Serrati ${ }^{1}$ \\ Kamila Carleto Fernandes ${ }^{2}$
}

\section{Resumo}

Vivemos a mais impactante pandemia da história mundial, causada pelo novo coronavírus, Sars-CoV-2. Diante da necessidade de isolamento social e do conjunto de estratégias e ações voltadas para o controle e informação acerca da pandemia que leva a COVID-19, surge a proposta deste relato de experiência. Objetivamos, contar como tem funcionado nesse contexto, os encontros de grupos de trabalho, reuniões com orientadoras, entrevistas, o processo de produção acadêmica e grupos de estudos, além de outras práticas. Entendemos o quanto a tecnologia tem sido necessária e potente na manutenção de nossos trabalhos e pesquisas, e acreditamos em uma prática inclusiva que abarque realidades na/para além da Universidade. Acreditamos que esses espaços e plataformas devem compor nossas práticas de forma suplementar, ou seja, como suporte ou acréscimo ao trabalho e por isso não acreditamos que essas condições devam se manter posteriormente a pandemia.

\section{Palavras-chave}

Mulheres acadêmicas. Pandemia. COVID-19. Práticas emergentes.

Recebido em: 14/08/2020 Aprovado em: 26/01/2021

\footnotetext{
${ }^{1}$ Mestranda em Psicologia na linha de pesquisa Processos Psicossociais em Saúde e Educação pela Universidade Federal de Uberlândia/UFU (2018-2020). Graduada (Bacharelado e Formação de Psicólogo) em Psicologia pela Universidade Federal de Uberlândia/UFU (2017). Membro do Fórum sobre Medicalização - Núcleo Uberlândia. Atua principalmente nos seguintes temas: Psicologia Histórico-Cultural, Psicologia e Educação, aprendizagem e desenvolvimento humano, atuação do psicólogo escolar e educacional, Medicalização da Educação, formação de educadores/professores, processos criativos e Arte.

E-mail: camilaserratti@gmail.com

${ }^{2}$ Possui graduação em Psicologia pela Universidade Federal de Uberlândia (2018). Durante a graduação, foi bolsista FAPEMIG por dois anos, desenvolvendo pesquisas sobre a Formação de Professores, na área de Psicologia Escolar e Educacional. Atualmente é mestranda (bolsista CAPES) no Programa de Pós-graduação em Psicologia na Universidade Federal de Uberlândia na linha de pesquisa Processos Psicossociais em Saúde e Educação.

E-mail: kamilacarleto@gmail.com
} 


\section{Abstract}

We live the most impactful pandemic in world history, caused by the new coronavirus, Sars-CoV-2. Given the need for social isolation and the set of strategies and actions aimed at controlling and informing about the pandemic that leads to COVID-19, the proposal for this experience report appears. We aim to tell how it has worked in this context, meetings of working groups, meetings with supervisors, interviews, the academic production process and study groups, in addition to other practices. We understand how powerful and necessary technology has been in maintaining our work and research, and we believe in an inclusive practice that embraces realities in / beyond the University. We believe that these spaces and platforms should be part of our practices in a supplementary way, that is, as support or addition to the work and therefore we do not believe that these conditions should continue after the pandemic.

\section{Keywords}

Academic women. Pandemic. COVID-19. Emerging practices. 


\section{Breve contextualização do cenário de trabalho durante a pandemia do COVID-19}

Enquanto escrevíamos este artigo, estávamos vivendo um evento inédito e a mais impactante pandemia da história mundial recente causada pelo novo coronavírus, Sars-CoV-2 - o desejo é que isso chegue ao fim em um intervalo curto de tempo, mas não temos certezas quanto a isso. A pandemia do COVID19 nos colocou em um cenário de "emergência de saúde pública", no qual a Organização Mundial de Saúde (OMS) instruiu que medidas restritivas drásticas fossem adotadas, para que aglomerações não acontecessem, com o intuito de reduzir a disseminação do vírus. Dentre diversas recomendações da OMS, está o isolamento horizontal, que foi adotado como medida obrigatória na grande maioria dos estados e municípios do Brasil e que tem sido a nossa realidade nesse período (Ministério da Saúde, 2020).

Nesse cenário pandêmico ainda não sabemos todas as dimensões dos impactos e os danos causados à saúde e à sociedade, porém temos percebido um fenômeno inusitado, ao qual precisamos lançar olhares atentos: a queda da produção científica de mulheres pesquisadoras. O cotidiano das pesquisadoras sofreu uma grande reviravolta no início do ano de 2020, o qual ficará marcado na memória de quem viveu esse momento, e na história de nosso país.

Entendemos que as revistas científicas são um importante mecanismo de divulgação acadêmica e são essenciais para o fomento da produção científica, e é no conjunto de estratégias e ações voltadas para o controle, manutenção do trabalho e divulgação de informações acerca da pandemia causada pela COVID19 e seus efeitos, que surge a proposta deste relato de experiência. É dentro desse contexto que nós, pesquisadoras inseridas no programa de pós-graduação, buscamos relatar nossas experiências dentro de múltiplos "conhecidos formatos" de trabalho.

Nesta escrita chamaremos os atuais modos de trabalho de "conhecidos formatos", pois o universo virtual já fazia parte de nossas vidas, e da vida de todas as outras pesquisadoras, em certa medida. O que temos de novo agora é o 
fato de que esse lugar que não é comum a todos - e falaremos mais sobre isso adiante -, é o único espaço possível para que nosso trabalho não cesse de vez. Também temos as diversas plataformas de comunicação, que se aperfeiçoam constantemente para dar conta das demandas do momento. O mundo virtual tem sido nosso espaço de trabalho, lugar de produção, construção, desconstrução, aprendizados e desafios. Tem sido nosso refúgio para contatar familiares, amigos e colegas de trabalho. Além de ser também, uma intensa fonte de informações, nossa janela para o mundo.

Assim, com o isolamento, o qual somos obrigadas a adotar para nos proteger, trabalhos que outrora funcionavam presencialmente tiveram que ser reinventados, repensados e reorganizados. Encontros de grupos de trabalho, reuniões com orientadoras, o processo de leitura e escrita, grupos de estudos, aulas e grupos abertos passaram a funcionar totalmente online, acompanhados da criação de grupos no Whatsapp. Os congressos tiveram que ser remarcados e começaram a acontecer através de plataformas virtuais de interação. Até mesmo as clínicas precisaram inovar para continuar existindo, se adaptando exclusivamente aos atendimentos online, seguindo as orientações apresentadas por cada respectivo Conselho e Código de Ética.

Se o trabalho de uma pesquisadora já trazia uma sensação de que era solitário, diante da pandemia esse sentimento se intensificou e acabou se concretizando. E como isso tem sido feito? Têm tido resultados positivos? Como essas mudanças e tantos impedimentos impactam pesquisas que se iniciaram em um contexto onde a vida "normal" ainda era possível? E como estão as mulheres pesquisadoras? As conversas apenas online com orientadoras e colegas de trabalho são tão benéficas quanto as presenciais? Ou melhor, são suficientes? Quando falamos de impedimentos, quais são eles? As perguntas e incertezas ainda são muitas.

Nosso objetivo nesta escrita é expor e falar sobre alguns questionamentos a partir do relato de nossas experiências de trabalho nesse cenário pandêmico. Não temos a intenção de trazer respostas prontas e definitivas, visto que ainda estamos em fase de descobertas dentro deste universo virtual que não tem sido 
uma escolha, mas sim, uma necessidade e uma alternativa que se apresenta como única. Assim como, não intentamos afirmar qual a maneira correta de se trabalhar nesse período, pois acreditamos que ao falar deste "novo normal", precisamos considerar as incontáveis realidades existentes, muitas das quais não conhecemos, mas sabemos que existem.

Sendo assim, enfatizamos que nosso objetivo é contar as nossas práticas e percepções. Esperamos que dessa forma, possamos contribuir para a ampliação de novos horizontes e possibilidades de trabalho durante a pandemia de COVID-19, e também, apresentar alguns questionamentos que possam facilitar ideias e mudanças para o mundo pós-pandemia.

\section{A realidade das pesquisadoras e a desigualdade entre os gêneros}

Temos a consciência de que muitas pesquisadoras se encontram em situações extremamente desafiadoras e, muitas vezes, sem as condições básicas para que possam continuar seu trabalho. Quais seriam essas condições? Ambiente reservado e silencioso para os processos de leitura e escrita, reuniões, entrevistas e quaisquer outros momentos que envolvam o contato e a troca com outrem; computador não compartilhado, ou seja, que fique $100 \%$ à disposição da pesquisadora quando ela precisar; acesso à internet de qualidade; dentre outros. Nota-se que falamos de questões socioeconômicas, porém poderíamos citar outras como se a pesquisadora tem filhos ou não, se é casada e existe divisão de tarefas domésticas e muitos outros pontos que fazem parte do dia a dia das mulheres.

Algumas informações nos mostram que as pesquisadoras têm sido muito afetadas nesse cenário, como por exemplo, a análise preliminar publicada em abril deste ano pelo jornal Inside Higher Education apresenta dados que indicam a queda de submissões de artigo por mulheres desde o início da COVID-19. Outro estudo, realizado no Brasil pelo projeto Parent in Science, idealizado por Fernanda Stanisçuaski, professora e pesquisadora do Instituto de Biociências da Universidade Federal do Rio Grande do Sul (UFRGS) e mãe, aponta que $13 \%$ das pós-graduandas possuem filhos. Com a suspensão das 
creches e escolas, o isolamento de maneira compulsória, o ensino remoto emergencial e consequentemente a necessidade de realizar as atividades da escola dos filhos em casa, indica que as pós-graduandas mães estão se desdobrando em jornadas duplas e triplas e, para além das suas jornadas de trabalho, se responsabilizaram ou foram responsabilizadas pelo cuidado da casa e dos filhos. (https://ufmg.br/comunicacao/noticias/produtividade-depesquisadoras-mulheres-e-mais-afetada-pela-pandemia, recuperado em 30 de julho de 2020).

Elizabeth Hannon, editora do British Journal for Philosophy of Science, expôs que a revista quase não teve submissões de trabalhos escritos por mulheres no mês de abril, ao que a editora escreve em suas redes sociais: "Nunca vi nada parecido" (https://revistapesquisa.fapesp.br/maes-na-quarentena/, recuperado em 29 de julho de 2020).

Não podemos negar as mudanças ocorridas na última década como a divisão mais igualitária nas tarefas domésticas, incluindo a participação de outras pessoas, como os parceiros, nos cuidados da casa. Não negamos também uma mudança no cuidado das crianças/filhos, visto que hoje existem banheiros masculinos com trocador de fraldas, por exemplo. Entretanto, ainda é pouco e é comum que as mulheres sejam sobrecarregadas na execução dessas tarefas e, acerca disso tratemos brevemente Marx e Engels (1985), que afirmaram que a emancipação da mulher e sua paridade com relação ao homem seguirão sendo impossíveis se ela continuar excluída do "trabalho produtivo social" e presa ao trabalho doméstico - trabalho privado. As mulheres só terão sua emancipação possível quando puder participar plenamente e com grandeza, do trabalho social; ficando o trabalho doméstico em segundo plano ocupando quantidade irrelevante de tempo.

Os dados que trouxemos são limitados, no sentido de que existe uma vasta quantidade de pesquisas que têm discutido sobre a temática e não acessamos todas, mas, mesmo assim, denunciam a realidade de muitas mulheres que não tem com quem dividir as tarefas e, ao ter que vivenciar a maternidade em tempo integral, apresentam queda da produtividade acadêmica - além de questões 
importantes que decorrem dessa sobrecarga, como cansaço, possível estresse, dentre outros pontos, porém aqui iremos abordar apenas a dificuldade em manter o ritmo de trabalho.

É importante lembrarmos ainda, que hoje, o sistema de avaliação da produtividade acadêmica é medido pela quantidade de publicação de artigos, o que torna as condições de concorrência entre homens e mulheres aos editais de financiamento ou progressão de carreira, também desigual.

Por isso, reconhecemos a necessidade de se abrir um debate acadêmico sobre quais são os caminhos possíveis para superar as desigualdades entre homens e mulheres tanto na escrita acadêmica quanto nos papéis sociais, incluindo aí a divisão das tarefas na maternidade e paternidade e das tarefas domésticas. $\mathrm{O}$ grupo Parent in Science apresenta uma proposta de "Maternidade no Lattes", que seria uma reivindicação de inclusão do período da licença-maternidade no currículo Lattes. Essa requisição tem um objetivo bem definido - sinalizar que alguma queda de produtividade acadêmica que ocorra nesse período seja justificada, e pensamos ser essa uma das alternativas possíveis.

Devemos pensar sobre eventuais procedimentos que incentivem e deem condições para que as mulheres consigam produzir academicamente de modo geral e durante a pandemia especificamente. Entretanto acreditamos que se a ciência é uma das nossas maiores aliadas na eventual saída desta crise pandêmica, cabe a nós questionarmos os mecanismos que nos afastam destes canais de intervenção e produção e porque não estamos ocupando estes espaços, bem como propor algumas possibilidades de enfrentamento.

\section{Impactos da pandemia na realidade de pesquisadoras}

Ao expormos as condições de mães/mães chefes de família e pesquisadoras, e as dificuldades enfrentadas nos trabalhos dentro da academia, precisamos contar que não partimos desse lugar de fala. Como uma forma de abrir o relato sobre nossas experiências práticas com o trabalho e as pesquisas, acreditamos ser de extrema importância expor nosso contexto e o lugar de onde falamos, pois o que 
iremos contar é o que tem funcionado para nós, diante da nossa realidade particular. Somos mulheres solteiras e sem filhos, possuímos computadores próprios, energia elétrica no local, um ambiente silencioso e uma cadeira confortável, e de nosso uso exclusivo, além de acesso à boa internet. Partimos de uma realidade em que o trabalho doméstico e as exigências diárias são poucas, quando comparadas com pesquisadoras mães/mães chefes de família, por exemplo. Entretanto, sentimos também o peso dessa mudança brusca, percebida no início como uma dificuldade em estabelecer horários para o desenvolvimento das pesquisas, tanto para começar o trabalho quanto para parar, visto que o instrumento de trabalho, o computador, é também o de lazer; contratempos ao agendar reuniões e orientações online; inconvenientes com problemas de conexão da internet; embaraços nos diálogos, pois ao não conseguir perceber bem as expressões faciais da outra pessoa, ou mesmo o tom de voz, a comunicação fica prejudicada. Assim, foi necessário adequar uma rotina que comportasse as horas de pesquisa e de leitura, as horas de sono e de execução das tarefas domésticas. Além disso, precisamos também, nos adaptar a essa realidade e reaprender a nos relacionar à distância, aprender a ser coletivo, mesmo estando longe.

\section{O caminho se faz ao caminhar: práticas possíveis}

Para tornar compreensível a maneira como temos pensado nossas práticas, precisamos pensar e explicar esse ambiente virtual de trabalho. Para isso, traremos as definições etimológicas de "ambiente" e "virtual" descritas por Grossi, Moraes \& Brescia (p. 3, 2013):

Etimologicamente a palavra ambiente possui sua origem no latim ambiens, que significa "volta ao redor", do verbo ambire, "ir ao redor", de AMBI-, "em volta, ao redor", mais IRE, "ir". Sendo assim, pode-se compreender que se refere a tudo que está envolta ou envolve coisas e ou pessoas.

A palavra virtual deriva-se do latim medieval virtualis, que tem sua procedência em virtus, -utis, podendo designar qualidades do homem, coragem, energia, potência. E não apenas o oposto ao real, como senso comum costuma definir o termo virtual.

Escolhemos apresentar algumas de nossas práticas em tempos de isolamento social a partir dessa definição, justamente por trazer o virtual como energia e potência, porque é o caminho que se apresenta como possível. Parar o trabalho 
não é uma opção, portanto, mesmo com as compreensões limitantes citadas acima, nosso olhar precisa estar voltado para as potências oferecidas, caso contrário ficaremos paralisadas. Acreditamos que, agora mais do que nunca, o trajeto vai tomando forma ao longo das práticas, como lindamente traz Antônio Machado em seu livro Campos de Castilla (1912), na parte intitulada "Provérbios y cantares", sob o número XXIX:

[...] Caminhante, não há caminho, o caminho se faz ao caminhar.

Sendo assim, nosso trabalho abraçou os "conhecidos formatos", e entendemos que eles são os únicos que tornam possível continuar desbravando caminhos durante a pandemia e nos manter seguras.

Adentrando em nossas práticas atuais, encontramos mudanças no formato do desenvolvimento do trabalho da pós-graduação, que passa a ser limitado, pois deixamos de ir a campo. Por sorte, muito da parte prática de nossas pesquisas já tinha se desenrolado, restando apenas uma entrevista final que pôde ser realizada através de uma plataforma que dispõe de chamada de vídeo, seguida da análise dos dados e dos diários de campo. Sendo assim, consideramos que nesse aspecto não tivemos dificuldades, muito pelo contrário, a tecnologia foi uma importante aliada nessa fase, oferecendo a possibilidade de execução de um trabalho que já estava em andamento, e que em outras condições, não seria possível.

Pensando na produção acadêmica, uma alternativa que encontramos para continuar construindo coletivamente os artigos e relatos de experiência, foi a escrita em conjunto pela plataforma Google Docs e realização de vídeo chamada através do Google Meet. Por essas plataformas foi possível compartilhar ideias ao mesmo tempo em que a escrita se desenvolvia. Este relato de experiência em questão foi pensado e construído desse modo.

Ainda dentro do contexto acadêmico, um curso de introdução à uma teoria específica havia sido planejado para acontecer entre os meses de abril a junho, de modo presencial, e seria ministrado por uma professora especializada na vida 
e obra do autor principal de tal teoria. Em decorrência da pandemia, não foi possível executá-lo. Entretanto, do desejo das alunas inscritas neste curso de estudarem o tema, surge a ideia de criar um grupo de estudos virtual, que tem acontecido quinzenalmente através da Plataforma Google Meet, sendo 100\% gratuito para todas e coordenado de maneira horizontal. São escolhidos os capítulos para serem lidos antes de cada encontro, e estes são debatidos a partir do aprofundamento com estudos de casos, além dos casos clínicos atendidos e levados pelas participantes. O grupo cresceu e hoje abarca pessoas que também não estavam inscritas no curso, mas que se interessam pela temática em questão.

Outra prática que não só tem sido possível nesse contexto, mas foi pensada a partir das consequências geradas pela pandemia, tem sido o Grupo de Mulheres. Esse Grupo surge através do Instagram, com a seguinte pergunta: “Qual tem sido a maior dificuldade do isolamento social?”, em que a intenção era simplesmente interagir. Porém, a maioria das respostas foi de mulheres falando sobre dificuldades no relacionamento amoroso. A partir daí, com a intenção de acolher cada uma, surge o Grupo de Mulheres Online, ainda sem nome próprio, que tem acontecido quinzenalmente através da Plataforma Google Meet, sendo 100\% gratuito para todas. Com o desenrolar dos encontros via Google Meet, as reuniões foram se transformando e sendo moldadas pelo coletivo, e hoje, somos uma turma que estuda temas acerca do universo da mulher, visando acolher e construir práticas que podem emancipar mulheres durante a pandemia de COVID-19.

Quando pensamos na experiência do Grupo de Mulheres, temos enfrentado poucas dificuldades, estando dentre elas as limitações na comunicação - falas sobrepostas, entrecortadas, impossibilidade de perceber a linguagem corporal e de acolher aquelas que se emocionam durante a conversa. Apesar disso, temos mais uma vez a internet tem sido uma grande aliada e tem possibilitado contato com mulheres de diferentes estados e regiões. Começamos com dez participantes e hoje já somos mais de trinta membros. Um ponto que acreditamos ser relevante sobre essa prática, é que, ao mesmo tempo em que a internet aproxima, ela também afasta e não podemos nos esquecer disso. 
Entendemos que alcançamos muitas mulheres e que com o crescimento rápido e constante do Grupo (alcançamos a marca de trinta participantes em um mês) temos intenção de ampliá-lo e torná-lo presencial, porém não sabemos quando isso será viável.

Percebemos que, mesmo com o crescimento do grupo, ainda assim estamos falando de um público específico, aquelas que têm computador, acesso à internet e à informação. Por isso, questionamos: quem acolhe a mulher que não tem acesso a esses meios de comunicação e não tem à disposição uma rede de apoio que acolhe e a escuta? Como ficam as mulheres de classes menos favorecidas diante de uma situação em que o trabalho é possível apenas para algumas? Não temos a intenção de responder essas perguntas, mas sim de provocar uma reflexão crítica acerca do que estamos chamando de práticas possíveis, além de questionar para quem essas práticas são possíveis.

Lançando o olhar sobre o indivíduo, pensar na prática clínica sempre nos fez pensar em afeto, troca e intensidade de sentimentos e emoções, por isso, os atendimentos online trouxeram, inicialmente, preocupação. Deixar de trabalhar, no entanto, não era uma opção. Assim, com a nota oficial do Conselho Federal de Psicologia (CFP) acerca da facilitação do cadastro no site do e-Psi para realização da psicoterapia online, tomamos as devidas providências e demos continuidade mais uma vez, no mundo virtual. Acreditamos que essa tem sido uma das maiores descobertas dentre nossas práticas durante o isolamento social, pois apesar de a psicoterapia online já ser regulamentada pelo CFP desde antes de a pandemia se tornar realidade, não fazia parte dos nossos dias. Temos aprendido que a qualidade dos atendimentos não diminui, e que as trocas fluem tão bem quanto presencialmente.

Como pesquisadoras na "era da sociedade da informação" ou "geração z", sempre fizemos uso dessas múltiplas ferramentas tecnológicas no dia a dia, e compreendemos a necessidade de a educação acompanhar as mudanças que a sociedade vive. Apesar disso, existe uma grande diferença entre utilizar alguns instrumentos tecnológicos durante o trabalho, e ter a tecnologia como único 
meio de trabalho. Essa é a grande e abrupta virada que sofremos no cenário pandêmico - como citamos anteriormente, não é a única.

\section{Considerações Finais}

Por estarmos inseridas no campo da psicologia acreditamos que o trabalho é feito de maneira conjunta, na relação com o outro. Muito se perde em qualidade quando comparamos os debates presenciais com os debates online, pensando em questões de velocidade da conexão da internet, alta resolução da tela, ou de acesso aos meios de transmissão. Por isso, acreditamos que para trabalhar com o possível, é preciso que as instituições de ensino ofereçam alternativas para que todos os alunos possam ter acesso a um computador e a internet para a execução de suas atividades, bem como ambiente propício aos estudos e tempo necessário para se dedicar à realização de produções.

Entendemos que o contexto virtual ainda não é inclusivo como gostaríamos que fosse, e a realidade pandêmica tem deixado muitas e muitos para trás. Afirmamos que o trabalho das(os) psicólogas(os), as pesquisas e também a educação nesse modelo virtual deve ser complementar/suplementar e não substitutiva, pois não podemos negar que ao mesmo tempo em que possibilita o diálogo e a troca, essa relação virtual é uma relação "incompleta" permeada pela falta do olhar, do cheiro, do toque, do mesmo espaço físico sendo compartilhado. Tais aspectos são importantes e fazem parte do processo de ensino e aprendizagem, porque os seres humanos pensam e sentem simultaneamente, o que mostra que existe uma "dimensão afetiva" presente nas relações e interações entre as pessoas e, também, entre as pessoas e as práticas e instrumentos pertencentes à cultura (Leite, 2018). Nesta linha de raciocínio, compreendemos o desenvolvimento como dependente do processo de aprendizagem (Vigotski, 1953).

Sem nos esquecer disso, reiteramos a necessidade de que as transformações no cenário educacional sejam rápidas, cuidadosas e efetivas. Como já relatamos, tivemos o privilégio (se é que podemos usar essa palavra ao pensar nas situações geradas pela pandemia) de nos encontrar em fases avançadas nas pesquisas da 
pós-graduação, visto que são pesquisas que demandaram presença em diversos espaços e contato físico com outras pessoas. Sendo assim, esse trabalho pôde dar seguimento para, sem grandes interferências. Porém, vivenciamos a partir daqui a orientação online com a professora em questão, através da Plataforma Virtual da própria Universidade. As trocas se mantêm ricas e potentes, tem sido possível compartilhar as dúvidas, as dificuldades do processo de escrita, e com isso, o aprendizado não foi interrompido.

Pensando em condições de aprendizado, Sérgio Leite e Ariane Tagliaferro (2006, p. 248) pontuam que:

A relação que se estabelece entre o aluno e o objeto do
conhecimento (no caso, os conteúdos escolares) não é somente
cognitiva, mas também afetiva. Isso mostra a importância das
práticas pedagógicas desenvolvidas pelo professor, pois as
mesmas estarão mediando a relação que se estabelece entre o
aluno e os diversos objetos do conhecimento envolvidos. Pode-
se assumir, portanto, que o sucesso da aprendizagem
dependerá, em grande parte, da qualidade dessa mediaçãa.

Em relação à pesquisa, as condições de produção perpassam por mecanismos de aprendizagem similares, entretanto devemos nos perguntar então como fica essa mediação em relação às produções acadêmicas? Se não se pode ir a campo, se as entrevistas são feitas online, e se não é possível ter a observação do âmbito de pesquisa, uma vez que o ambiente possível é virtual.

Com experiências tão ricas sendo facilitadas pelas plataformas virtuais, acreditamos que são importantes e necessárias, afinal de contas, nosso trabalho se mantém através delas. Devido a pandemia do novo coronavírus vivemos essa única possibilidade. Porém, apesar disso, reiteramos que esses espaços e plataformas devem compor nossas práticas de forma suplementar, ou seja, como suporte ou acréscimo ao trabalho. Não acreditamos que essas condições devam se manter posteriormente a pandemia, no que está sendo chamado de "novo normal", pois como já exposto, esse cenário é excludente e portanto, oposto ao que a psicologia enquanto ciência e profissão propõe. 
Acreditamos em uma prática inclusiva, na qual as pesquisas avancem para além da produção na/para as Universidades, alcançando a população como um todo, mesmo em tempos de pandemia. Com relação às práticas psicológicas, acreditamos que elas devam retornar para os espaços físicos, assim que for possível. A psicologia é construída através da relação entre os seres humanos, e quando isso se dá através de uma plataforma virtual, a interação é prejudicada.

\section{Referências}

BRASIL [MS]. (2020). Ministério da Saúde. [homepage on the Internet]. Sobre a doença: O que é COVID-19. Recuperado de https://coronavirus.saude.gov.br/sobre-a-doenca\#o-que-e-covid

DE FRANÇA FILHO, Astrogildo Luiz; DA FRANÇA ANTUNES, Charlles; CAMPOS COUTO, Marcos Antonio. ALGUNS APONTAMENTOS PARA UMA CRÍTICA DA EaD NA EDUCAÇÃO BRASILEIRA EM TEMPOS DE PANDEMIA. Revista Tamoios, [S.l.], v. 16, n. 1, maio 2020. ISSN 1980-4490. Disponível em: <https://www.e-publicacoes.uerj.br/index.php/tamoios/article/view/50535>. Acesso em: 31 jul. 2020. doi:https://doi.org/10.12957/tamoios.2020.50535.

GROSSI, M. G. R.; MORAES, A. L.; \& BRESCIA, A. T. (2013). Interatividade em ambientes virtuais de aprendizagem no processo de ensino e aprendizagem na educação a distância. @ rquivo Brasileiro de Educação, 1(1), 75-92.

LEITE, S. A. da S.; TAGLIAFERRO, A. R. A afetividade na sala de aula: um professor inesquecível. Psicol. Esc. Educ. (Impr.), Campinas, v. 9, n. 2, p. 247260, Dec. 2005. Available from http://www.scielo.br/scielo.php?script=sci_arttext\&pid=S1413$85572005000200007 \& \operatorname{lng}=$ en\&nrm=iso $>$. access on 31 July 2020. https://doi.org/10.1590/S1413-85572005000200007.

LEITE, S. A. da S. Bases teóricas do grupo do afeto. In: LEITE, Sérgio Antônio da Silva Afetividade: as marcas do professor inesquecível. (Org.) MACHADO, A. (1912). Campos de Castilla. Parte "Provérbios y Cantares", n. XXIX.

MARX, Karl; ENGELS, Friedrich. Manifesto do Partido Comunista. $5^{\mathrm{a}}$. ed., São Paulo: Global, 1985.

VIGOTSKI, L. S. (1956). Pensamento e Linguagem. São Paulo: Martins Fontes. 